\title{
INDEX OF VOLUME 52
}

Subjects:

\section{INDEX OF ABSTRACTS ${ }^{1}$}

Algebra and Theory of Numbers, 61, 231, 414, 612, 808, 1003.

Analysis, 63, 233, 423, 613, 813, 1005.

Applied Mathematics, 68, 238, 432, 617, 822, 1010.

Geometry, 69, 240, 435, 619, 823, 1013.

Logic and Foundations, 71, 241, 438, 1015.

Statistics and Probability, 72, 242, 439, 621, 826, 1016.

Topology, 73, 242, 440, 622, 829, 1016.

Authors:

Agnew, R. P., 43 (51; 877), 972 (813), 973 (814); Albert, A. A., 403 (231), 596 (414); Ambrose, W., (1005); Amundson, N. R., 43 (63); Ancochea, G., 973 (1013); Arens, R. F., 970 (622), 973 (829), 973 (829), (1005); Atkins, H. P., 973 (814).

Baer, R., 403 (240), 591 (435), 596 (414); Bankier, J. D., 973 (814); Barankin, E. W., 598 (64); Bateman, P. T., 971 (808); Bates, G. E., 595 (414); Beckenbach, E. F., 48 (51; 657); Becker, H. W., 595 (415), 596 (415), 973 (826), (1010), (1016); Beesley, E. M., 49 (64); Bell, P. O., 595 (51; 662), (1014); Bellman, R., 591 (613); Bergman, S., 972 (814), 973 (614); Bernstein, F., 970 (622); Bers, L., 42 (64), 42 (73), (1005), (1006); Bing, R. H., 42 (73), 403 (242), 403 (243), 596 (423), 973 (829); Birkhoff, G., 403 (241), 591 (423), 591 (617), 972 (808); Birkhoff, G. D., 403 (241), 973 (829); Birnbaum, Z. W., 599 (621); Blackwell, D., 971 (826); Blake, A., 403 (242); Blanch, G., 403 (233); Blumenthal, L. M., 43 (69), 596 (619); Boas, R. P., 590 (614); Bochner, S., (1016); Boschan, P., 973 (826); Bourgin, D. G., 42 (51; 887), 43 (64), 43 (64), 596 (423); Brauer, A. T., 591 (415), 591 (415), 973 (808), (1003); Brauer, R., 41 (61), 42 (51; 875), 581; Brinkmann, H. W., (1003); Brown, B. L., 591 (231); Brown, G. W., 403 (242); Brown, J. P., (815); Buck, E. F., 973 (809), Buck, R. C., 403 (233), 403 (233), 590 (423), 971 (809), 973 (809), (1006), (1006); Burton, L. J., 591 (423); Busemann, H., 972 (620).

Cairns, S. S., 581; Cameron, R. H., 42 (65), 596 (424); Camp, C. C., 973 (815), Caton, W.B., 596 (424); Chang, S. C., 43 (69); Chen, W. M., 590 (424); Chernoff, H., 402 (65), 403 (234), (1011); Civin, P., 42 (51; 878), 403 (234); Clarkson, J. A., 971 (815); Coburn, N., 591 (432); Cohen, I. S., 590 (416); Coler, M. A., 591 (416); Court, N. A., 972 (620); Cowling, V. F., (1006), (1007); Coxeter, H. S. M., 41 (51; $884), 43(51 ; 884), 48(51 ; 884), 591(416), 591(435), 971(612), 973(612,1092)$; Craig, H. V., 974 (816).

DeCicco, J., 43 (68), 43 (70), 404 (70), 590 (436), 596 (435), 597 (436), 597 (437), (824), (1014), (1014); Dilworth, R. P., 598; Dolph C. L., (1007); Doob, J. L., 43 (51; 886), 965; Dowker, C. H., 402 (243), (1017); Doyle, T. C., 402 (241); Dubisch, R., 974 (612); Dudley, D. W., 973 (822); Duffin, R. J., 403 (238), 974 (617); Dunford, N., 403 (424); Dye, L. A., $972(823)$.

Eberlein, W. F., 596 (433), 974 (614), (1007); Ehrlich, G., 591 (415); Eilenberg, S., 595 (416), 596 (417), 596 (417), 973 (1017); Emch, A., 591 (436), 596 (435), (435); Epstein, B., 590 (425), 972 (816); Erdös, P., 42 (61); Everett, C. J., 974 (809); Eves, H. W., 599 (241).

Fan, K., (1017); Federer, H., 590 (425), 970 (830); Feller, W., 43 (72), 43 (72), 591 (439), 591 (439); Fine, N. J., 973 (816); Floyd, E. E., 591 (440); Fox, R. H.,

${ }^{1}$ Numbers within parentheses refer to the page numbers for abstracts, and those outside parentheses refer to the pages for titles as listed in reports of meetings. 
(1017); Frame, J. S., 971 (810); Frank, E., 596 (234), 974 (614); Friedrichs, K. O., 590 (426), 591 (425), 591 (426), 592 (426); Frink, O., 971 (612); Fry, C. G., 971 (818); Fullerton, R. E., 402 (234).

Gage, W. H., 598 (428); Gaskell, R. E., (1011); Gelbart, A., 42 (64), 42 (73); Goffman, C., 591 (439); Goheen, H. E., (1011); Goldberg, M., 972 (824); Good, R. A., 592 (417), 596 (418), (417); Goodman, A. W., 971 (816); Gottschalk, W. H., 592 (441), 974 (622); Gould, S. H., 971 (817); Greenstone, L., 403 (235); Greer, E., (1014); Griffiths, L. W., 595 (418); Grove, V. G., 972 (824), Gustin, W., $48(51$; 888), 598 (426).

Hall, D. W., 590 (441); Hall, M., 590 (231); Halmos, P. R., 42 (72), 590 (427); Harrold, O. G., 48 (73); Haskell, R. N., (817); Hedlund, G. A., 974 (622); Heins, A. E., 43 (65); Heins, M. H., 974 (817); Helsel, R. G., 595 (441); Hemmingsen, E., 402 (243); Herriot, J. G., 971 (817); Herzog, F., 43 (51; 519); Hestenes, M. R., 595 (615), 596 (427); Hewitt, E., 403 (442), 404 (442), 404 (442), 595 (442), (442); Hill, J. D., 43 (51; 519), 404 (235); Hille, E., 403 (427); Hoel, P. G., 974 (827); Horn, A., 598 (427), (1007); Hsiung, C. C., 972 (824); Hu, S. T., (1018); Hua, L. K., 404 (232), 596 (418); Huff, G. B., 42 (70), 597 (436), 597 (443); Huff, W. N., (1008); Hughes, H. K., 971 (818); Hurewicz, W., 973 (830).

James, R. C., (1008); James, R. D., 598 (428); Jehle, H., 403 (238); Jennings, S. A., 972 (810); Johnson, R. E., 597 (232); Jones, A. W., 595 (418); Jones, B. W., 41 (61); Jones, F. B., 42 (74), 595 (243).

Kac, M., 43 (65), 971 (621); Kalisch, G. K., 404 (232), 972 (419); Kaplan, W., 596 (433); Kaplansky, I., 42 (61), 595 (419), 972 (613); Karush, W., 972 (615); Kasner, E., 43 (68), 404 (70), 590 (436), 597 (436), 597 (437), (824); Katz, L., 971 (827); Kelley, J. L., 42 (74), 402 (443), 970 (622); Kimball, B. F., 974 (827); Kiokemeister, F., 597 (232), 597 (419), 597 (419), 597 (420); Kiss, S. A., 42 (62); Kohn, W., 404 (235); Kolchin, E. R., (1003), (1004); Krzywoblocki, M. Z., (1008).

Lehmer, D. H., 403 (232); Levene, H., 971 (621, 1092); Levy, H., 595 (437); Lewis, D. C., 973 (829), 974 (818); Lewy, H., 48; Ling, D. P., 404 (241); Loewner, C., $42(66)$.

McCoy, N. H., 591 (231); McEwen, G. F., 598 (618); McKinsey, J. C. C., (613); Mackey, G. W., 592 (615), (1009); MacLane, G. R., 971 (615), 974 (818); MacLane, S., 595 (416), 596 (417), 596 (417), 973 (1017); Mandelbrojt, S., 974 (818); Martin, W. T., 42 (65), 596 (424); Masani, P. R., 974 (819), 974 (819); Meserve, B. E., 974 (810); Minakshisundaram, S., 590 (428); Mitchell, J. M., 972 (819); Montgomery, D., 42 (51; 888), (1016), (1018); Moore, C. N., 971 (810); Morse, A. P., 49 (64), (1009); Morse, M., 581; Moses, I. R., 973 (811); Munroe, M. E., 597 (428); Myers, S. B., 42 (74), (1018).

Nachbin, L., 592 (428); von Neumann, J., 402 (67); Niven, I., 42 and 1092 (62); Norris, N., (1016).

Opatowski, I., 42 (73), $43(51 ; 886), 592$ (440), 597 (440).

Pall, G., 43 (62); Phillips, R. S., 403 (238); Piranian, G., 597 (429), 972 (820); Pitcher, E., 42 (74), 402 (443), (1018), (1019); Polachek, H., 403 (239), (1011); Pollard, H., 402 (236), 404 (236), 590 (616), 974 (820), 974 (820); Poritsky, H., 973 (822); Post, E. L., (1015); Prager, W., 970 (822); Prenowitz, W., (1015); Protter, M. H., 974 (616).

Rad6, T., 36, 972 (620), 974 (620); Reade, M., 596 (429); Reichelderfer, P. V., (1009); Reid, W. T., 974 (820); Reissner, E., 404 (239); Rickart, C. E., 975 (811); Ringenberg, L. A., 592 (429); Roberts, J. H., 590 (443); Roberts, R. C., (1012); Robinson, L. B., 404 (66), 404 (66); Robinson, R. M., 971 (811), (1004); Roettinger, 
I., 597 (433); Rosenbaum, I., 591 (242), 592 (438); Rosenbloom, P. C., (1009); Rothe, E. H., 595 (429); Rubin, H., 971 (827); Ryser, H. J., 974 (809).

Salzer, H. E., 404 (68), 404 (69), 592 (420), 592 (433), 975 (618), (1012), (1012); Samelson, H., 42 (51; 888); Samuelson, P. A., 592 (239), 592 (239), 592 (240); Satterthwaite, F. E., 971 (828); Schaaf, S. A., 970 (618), (1013); Schaeffer, A. C., 598 (430); Schafer, A. T., (1015); Schafer, R. D., 597 (420), 975 (812); Schatten, R., 402 (67), 592 (430); Schiffer, M., 43 (67), 404 (236); Schilling, O. F. G., 594; Schwartz, A., 590 (437); Schweigert, G. E., 595 (443); Schweitzer, A. R., 42 (71), 42 (72), 597 (420), 597 (421), 975 (812), 975 (812), (1004), (1004); Scott, W. T., (1009); Seeger, R. J., (1011); Segal, I. E., 402 (237), 590 (422), 592 (421), 975 (616), (1010); Sheffer, I. M., 591 (422), 972 (820); Shen, Y. C., 592 (430); Sherman, S., 975 (434); Sholander, M. C., (813); Shü, S. S., 975 (822); Slater, J. C., 36; Smith, P. A., 592 (430); Snapper, E., 48 (63), 48 (63); Sobczyk, A., 596 (434); Sorgenfrey, R. H., 48 (75), (623); Spencer, D. C., 598 (430); Spitzbart, A., 975 (821); Springer, C. E., 43 (70); Steenrod, N. E., 595 (444); Stephens, C. F., 43 (67); Stone, M. H., 965; Sugar, A. C., 49 (69), 592 (619), 970 (619), 975 (619); Supnick, F., 590 (444), 592 (431), 592 (431), 592 (444), 593 (431), 975 (825), 975 (830), 975 (830), 975 (831), (1013), (1019); Swift, J. D., 598 (422), (1005); Synge, J. L., 972 (823); Szász, O., 590 (428), 972 (616).

Thomas, J. M., 404 (232), (813); Thomas, T. Y., 48 (71), 48 (71); Tong, H., 590 (617); Tornheim, L., 403 (233); Trjitzinsky, W. J., 975 (821); Truesdell, C. A., 591 (240), 970 (823); Tschen, Y. W., 971 (821); Tukey, J. W., 403 (242), 971 (828).

Ulam, S. M., 36.

Valentine, F. A., 48 (75); Van Straten, P., 975 (831); Vest, M. L., 975 (825); Vinograde, B., 597 (422).

Walker, G. W., 972 (825); Wall, H. S., 597 (431), (1009); Wallace, A. D., 402; Ward, M., 598 (423); Warschawski, S. E., 42 (68); Wasow, W. R., 590 (426); Wedderburn, J. H. M., (813); Weinstein, A., 404 (240), 590 (431), 970 (823); Whitehead, G. W., 402 (244), 590 (445); Whitman, P. M., 972 (808), (1005); Whitney, H., 965; Wiener, N., 43 (65); Wilder, R. L., 595 (445), 597 (445), 597 (446), 597 (446); Wilkins, J. E., 596 (432), (1010); Wolf, F., 972 (821); Wolfowitz, J., 975 (828); Wong, Y. C., 593 (438), 593 (438).

Young, G. S., 595 (443), 595 (446); Youngs, J. W. T., 43 (68), 590 (441), 595 (447), 970 (831).

Zariski, O., 975 (1015); Zimmerberg, H. J., 404 (237), 590 (237), 593 (432); Zorn, M. A., (237).

\section{INDEX OF REPORTS OF MEETINGS AND MISCELLANEOUS ARTICLES}

Banach, S. See Ulam, S.

Birkhoff, G. D. See Morse, M.

Bruck, R. H. Reports of meetings of the American Mathematical Society: Annual meeting of the Society, 35; A pril meeting in Chicago, 594.

Curtiss, D. R. Thomas Franklin Holgate, 1859-1945, 189.

Hildebrandt, T. H., and Kline, J. R. Memorandum concerning the deferment of graduate students, teachers, and research workers in physical science, 31 .

Holgate, T. F. See Curtiss, D. R.

Hollcroft, T. R. Reports of meetings of the American Mathematical Society: February meeting in New York, 401; April Meeting in New York, 580; Summer meeting in Ithaca, 964.

Kline, J. R. See Hildebrandt, T. H. 
Morse, M. George David Birkhoff and his mathematical work, 357.

Schaeffer, A. C. Reports of meetings of the American Mathematical Society: November meeting in Pasadena, 48; A pril meeting in Berkeley, 598.

Ulam, S. Stefan Banach, 1892-1945, 600.

\section{INDEX OF BOOK REVIEWS}

Baer, R. See Jacobson, N.

Barzun, J. See Hadamard, J.

Brauer, R. See MacDuffee, C. C.

Chebyshev, P. L. Collected works. Vol. 1. Theory of Numbers. J. V. Uspensky, 50.

Hadamard, J. An essay on the psychology of invention in the mathematical field. J. Barzun, 222.

Hay, G. E. See Sokolnikoff, I. S.

Jacobson, N. The theory of rings. R. Baer, 220.

Littlewood, J. E. Lectures on the theory of functions. D. C. Spencer, 51.

Lorch, E. R. See National Bureau of Standards.

MacDuffee, C. C. Vectors and matrices. R. Brauer, 405.

Mosak, J. L. General equilibrium theory in international trade. P. A. Samuelson, 52.

National Bureau of Standards. Table of $\operatorname{arc} \sin x$. E. R. Lorch, 224.

- Tables of associated Legendre functions. E. R. Lorch, 224.

Neville, E. H. Jacobian elliptic functions. W. Seidel, 604.

Ostrowski, A. Vorlesungen uber differential- und integralrechnung. Vol. I. Funktionen einer variablen. A. E. Taylor, 798.

Samuelson, P. A. See Mosak, J. L.

Schwartz, L. Etude des sommes d'exponentielles réelles. O. Szász, 976.

Seidel, W. See Neville, E. H.

Sokolnikoff, I. S. Mathematical theory of elasticity. G. E. Hay, 976.

Spencer, D. C. See Littlewood, J. E.

Szász, O. See Schwartz, L.

Taylor, A. E. See Ostrowski, A.

Uspensky, J. V. See Chebyshev, P. L.

\section{INDEX OF ADDRESSES}

Cairns, S. S. The triangulation problem and its role in analysis, 545 .

Chern, S. S. Some new viewpoints in differential geometry in the large, 1.

Lewy, $\mathrm{H}$. Water waves on sloping beaches, 737.

Schilling, O. F. G. Ideal theory on open Riemann surfaces, 945.

Slater, J. C. Physics and the wave equation, 392.

Walsh, J. L. Taylor's series and approximation to analytic functions, 572.

\section{INDEX OF RESEARCH PAPERS}

Agnew, R. P. A simple sufficient condition that a method of summability be stronger than convergence, 128.

Arens, $R$. The space $L^{\omega}$ and convex topological rings, 931.

Artin, E., and Whaples, G. A note on axiomatic characterization of fields, 245.

Atkins, H. P. On fractional derivatives of univalent functions, 1060.

Baer, R. Polarities in finite projective planes, 77.

- Projectivities with fixed points on every line of the plane, 273.

Absolute retracts in group theory, 501. 
Bing, R. H. Generalizations of two theorems of Janiszewski. II, 478.

- The Kline sphere characterization problem, 644.

Boas, R. P., and Pollard, H. Properties equivalent to the completeness of $\left\{e^{-t t^{\lambda}}\right\}, 348$.

Bobonis, A. A sufficiency theorem for differential systems, 465.

Bochner, S. Bloch's theorem for real variables, 715.

- Vector fields and Ricci curvature, 776.

Bourgin, D. G. Approximate isometries, 704.

Brauer, A., and Ehrlich, G. On the irreducibility of certain polynömials, 844.

Byrne, L. Two brief formulations of Boolean algebra, 269.

Cairns, S. S. See Index of Addresses.

Chandrasekharan, K. On the summation of multiple Fourier series. III, 474.

Chern, S. S. See Index of Addresses.

Civin, P. Polynomial dominants, 352.

Cohen, I. S. Note on a note of H. F. Tuan, 175.

Cohen, I. S., and Seidenberg, A. Prime ideals and integral dependence, 252.

Cohn, H. Note on almost-algebraic numbers, 1042.

Copeland, A. H., and Erdös, P. Note on normal numbers, 857.

Cowling, V. F. A generalization of a theorem of LeRoy and Lindelöf, 1065.

Dilworth, R. P. Note on the Kurosch-Ore theorem, 659.

Duffin, R. J. Nonlinear networks. I, 833.

Dunford, N., and Segal, I. E. Semi-groups of operators and the Weierstrass theorem, 911.

Eberlein, W. F. A note on the spectral theorem, 328.

Ehrlich, G. See Brauer, A.

Erdös, P. On the Hausdorff dimension of some sets in Euclidean space, 107.

- On the coefficients of the cyclotomic polynomial, 179.

- On some asymptotic formulas in the theory of partitions, 185.

Some remarks about additive and multiplicative functions, 527.

See Copeland, A. H.

Erdös, P., and Kac, M. On certain limit theorems of the theory of probability, 292.

Erdös, P., and Niven, I. Some properties of partial sums of the harmonic series, 248.

Erdös, P., and Rosenbloom, P. C. Toeplitz methods which sum a given sequence, 463.

Erdös, P., and Stone, A. H. On the structure of linear graphs, 1087.

Everett, C. J. Representations for real numbers, 861.

Floyd, E. E. On the extension of homeomorphisms on the interior of a two cell, 654.

Forsythe, A., and $\mathrm{McCoy}, \mathrm{N}$. H. On the commutativity of certain rings, 523.

Frank, E. On the zeros of polynomials with complex coefficients, 144.

The location of the zeros of polynomials with complex coefficients, 890.

Fried, H. On analytic functions with bounded characteristic, 694.

Fuchs, W. H. J. On a generalization of the Stieltjes moment problem, 1057.

Goldman, O. A characterization of semi-simple rings with the descending chain condition, 1021.

- Semi-simple extensions of rings, 1028.

Goldstine, H. H. See Moore, E. H.

Gottschalk, W. H. A note on pointwise nonwandering transformations, 488.

- Almost periodicity, equi-continuity and total boundedness, 633.

Gottschalk, W. H., and Hedlund, G. A. Recursive properties of transformation groups, 637.

Griffiths, L. W. A note on linear homogeneous diophantine equations, 734.

Gustin, W. Countable connected spaces, 101.

Haskell, R. N. Areolar monogenic functions, 332. 
Hedlund, G. A. See Gottschalk, W. H.

Heins, M. On the number of 1-1 directly conformal maps which a multiply-connected plane region of finite connectivity $p(>2)$ admits onto itself, 454.

Herzog, F. See Stewart, B. M.

Hewitt, E. A remark on density characters, 641.

Hildebrandt, T. H. See Moore, E. H.

Hua, L. K. Errata for A remark on a result due to Blichfeldt, 1092.

Huff, G. B. Inequalities connecting solutions of Cremona's equations, 287.

Huskey, H. D. A note on the area of a nonparametric surface, 720.

Jackson, D. The boundedness of orthonormal polynomials on certain curves of the third degree, 899.

Jones, F. B. Concerning the separability of certain locally connected metric spaces, 303.

Kac, M. See Erdös, P.

Kakutani, S., and Mackey, G. W. Ring and lattice characterizations of complex Hilbert space, 727.

Kalisch, G. K. On uniform spaces and topological algebra, 936.

Kaplansky, I. On a problem of Kurosch and Jacobson, 496.

Kiokemeister, F. The Asano postulates for the integral domains of a linear algebra, 490.

Lehmer, D. H. Two nonexistence theorems on partitions, 538.

Levitzki, J. On a problem of $A$. Kurosch, 1033.

Lewy, H. See Index of Addresses.

Loomis, L. H. A note on the Hilbert transform, 1082.

McCoy, N. H. See Forsythe, A.

Mackey, G. W. Note on a theorem of Murray, 322.

- A remark on locally compact abelian groups, 940. See Kakutani, S.

Mendelsohn, N. S. Symbolic solution of card matching problems, 918.

Moore, E. H. Classes of sequences of positive numbers (Prepared for publication by H. H. Goldstine and T. H. Hildebrandt.), 192.

Motzkin, T. Errata for A 5 curve theorem generalizing the theorem of Carnot, 1092.

- Errata for The hypersurface cross ratio, 1092.

- Errata for The pentagon in the projective plane, with a comment on Napier's rule.

Munroe, M. E. A note on weak differentiability of Pettis integrals, 167. A second note on weak differentiability of Pettis integrals, 668.

Niven, I. See Erdös, P.

Olds, C. D. Note on an asymmetric Diophantine approximation, 261.

Pinney, E. The electrostatic field of two coplanar plates, 838.

Piranian, G. A summation matrix with a governor, 882.

Pollard, H. The representation of $e^{-x \lambda}$ as a Laplace integral, 908. See Boas, R. P.

Post, E. L. A variant of a recursively unsolvable problem, 264.

Reid, W. T. A note on the Du Bois-Reymond equations in the calculus of variations, 158.

Richardson, M. On weakly ordered systems, 113.

Riordan, J. Derivatives of composite functions, 664.

Robbins, H. On the $(C, 1)$ summability of certain random sequences, 699.

Rosenbloom, P. C. Some properties of absolutely monotonic functions, 458.

- See Erdös, P.

Samelson, H. A note on Lie groups, 870.

Santal6, L. A. A geometrical characterization for the affine differential invariants of a space curve, 625. 
Schafer, R. D. Equivalence in a class of division algebras of order $16,874$.

Schilling, O. F. G. See Index of Addresses.

Schwerdtfeger, H. Moebius transformations and continued fractions, 307.

Segal, I. E. Topological groups in which multiplication of one side is differentiable, 481. - See Dunford, $N$.

Seidenberg, A. See Cohen, I. S.

Shah, S. M. On proximate orders of integral functions, 326.

- On the lower order of integral functions, 1046.

On the singularities of a class of functions on the unit circle, 1053.

Sheffer, I. M. Note on multiply-infinite series, 1036.

Slater, J. C. See Index of Addresses.

Spitzbarg, A. Approximation in the sense of least pth powers with a single auxiliary condition of interpolation, 338, 1092.

Stewart, B. M., and Herzog, F. Cylinders in a cone, 94.

Stone, A. H. See Erdös, P.

Uhler, H. S. Note on the Mersenne numbers $M_{157}$ and $M_{167}, 178$.

Valentine, F. A. Set properties determined by conditions on linear sections, 925.

Wall, H. S. Continued fraction expansions for functions with positive real parts, 138.

- A theorem on arbitrary $J$-fractions, 671.

Reciprocals of $J$-matrices, 680.

Bounded J-fractions, 686.

Walsh, J. L. Note on the location of the critical points of harmonic functions, 346.

- On degree of approximation on a Jordan curve to a function analytic interior to the curve by functions not necessarily analytic interior to the curve, 449.

See Index of Addresses.

Wang, F. T. A note on the Riemann zeta-function, 319.

Whaples, G. See Artin, E.

Whitman, P. M. Lattices, equivalence relations, and subgroups, 507.

Whyburn, G. T. On monotone retractability into simple arcs, 109.

Woods, C. L. A restricted class of convex functions, 117.

Young, G. S. Spaces congruent with bounded subsets of the line, 915.

Zorn, M. A. Derivatives and Frêchet differentials, 133.

Zygmund, A. On the theorem of Féjer-Riesz, 310. 